\title{
MORPHOMETRIC STUDY OF PROXIMAL END OF FEMUR IN
} TELANGANA POPULATION

\section{Vinay $\mathrm{G}^{1}$, Naveen Kumar B ${ }^{* 2}$, Kalpana Thondapu ${ }^{3}$.}

${ }^{1}$ Professor \& Head, Department of Anatomy, Mamata Medical College, Khammam, Telangana, India.

${ }^{* 2}$ Associate Professor, Department of Anatomy, Mamata Academy of Medical Sciences, Hyderabad, Telangana, India.

${ }^{3}$ Associate Professor, Department of Anatomy, Mamata Medical College, Khammam, Telangana, India.

\section{ABSTRACT}

Introduction: The surgeries over the proximal end of femur is common procedure in orthopaedics. Knowledge of proximal femur's morphometry can be helpful in reducing the risk of complications linked to surgeries done in this region due to vascular, metabolic or traumatic causes. The present study is therefore conducted to provide data on the morphometric values of proximal femur and to customize the implant design to suit the Telangana population and thereby reducing the complications.

Objectives: 1.To study the various measurements of proximal end of femur 2. To compare the results with previous studies.

Materials and Methods: A total of 180 dry femur have been collected from Department of Anatomy, Mamata Medical College. With the aid of the vernier calliper, goniometer and osteometric board, measurements such as femoral length, transverse diameter of the head, anterior neck length and angle of the neck shaft were measured.

Results: The average length of the left femur was $43.33 \pm 2.72 \mathrm{~cm}$ and $42.95 \pm 3.29 \mathrm{~cm}$ of the right femur. The anterior neck length of the right femur was $2.69 \pm 0.41 \mathrm{~cm}$, and left femur was $2.61 \pm 0.34 \mathrm{~cm}$. The neck shaft angle of left femur was $120.3^{\circ} \pm 5.26$ and right femur was $119.92^{\circ} \pm 6.27$.

Conclusion: Relative to other populations, this study showed the measurements of proximal femur in Telangana population were different. The results of this study can be significant in anthropological and medico-legal practice as well as for the diagnosis and treatment planning of radiologists and orthopaedic surgeons.

KEY WORDS: Femur, Proximal end, Morphometry, Neck shaft angle.

Corresponding Author: Dr Naveen Kumar B, Associate professor, Department of Anatomy, Mamata Academy of Medical Sciences, Hyderabad - 500090, Telangana, India.

E-Mail: anatmmc@gmail.com

Access this Article online

Quick Response code

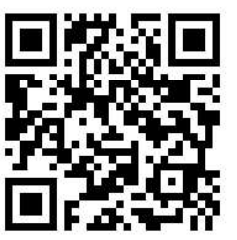

DOI: $10.16965 /$ ijar.2019.350

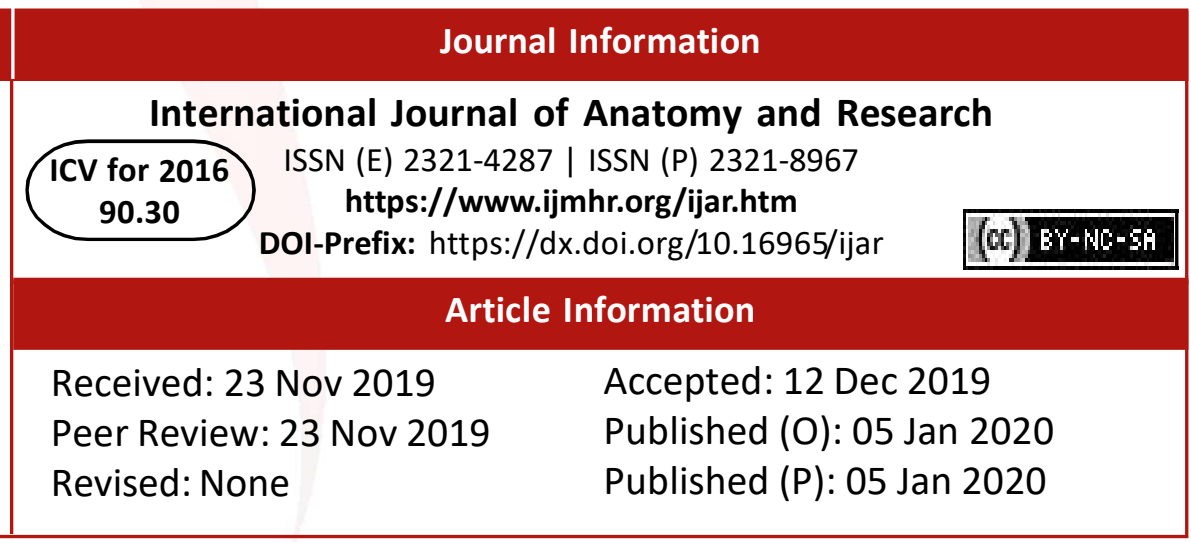

\section{INTRODUCTION}

The femur or thigh bone is the human body's longest and strongest bone. It has proximal end, shaft and distal end. The proximal end comprises of head, neck, greater and lesser trochanters [1]. The head of the femur articulates with the acetabulum of hip bone to form the ball and socket variety of synovial hip joint [2]. Femoral neck is a cylindrical strut of bone which links the head to the shaft of the femur and is about $5 \mathrm{~cm}$ in length. The neck of femur has functionally modified due to the erect posture of humans [3]. 
The angle created by the longitudinal axis of the neck with the longitudinal axis of the shaft of femur bone is termed as neck shaft or collo-diaphysial angle. The neck shaft angle ranges from $115^{\circ}$ to $140^{\circ}$, and an average of $126^{\circ}$ in adults. When the angle $>135^{\circ}$, condition is known as coxa valga. When angle $<120^{\circ}$ called as coxa vara. The collodiaphysial angle decreases with aging [4]. This angle of neck shaft allows the limb to swing clear of the pelvis during movements at the hip joint [5]. It is highest in infants decreases gradually with age [6], and the angle is greater in males than females [7].

The knowledge of morphometry of proximal end of femur is important because it varies with different ethnicity and individuals. It is quite normal to have proximal femur fractures, including neck and trochanters. For the early recovery and rehabilitation of patients, internal fixation of these fractures using implants is essential [8].

The implants used for surgical treatment of femoral fractures including dynamic hip screws, cancellous screws, blade and plates are designed according to the measurements of proximal femur. These implants are exclusively designed based on the western measurements [9]. The present study therefore aims to evaluate the morphometry of proximal end of femur of Telangana population and to compare it with similar studies. It may also be useful for biomechanics in designing and creating implants for the local population.

\section{MATERIALS AND METHODS}

This is an observational, descriptive study on 180 dry adult femora which were randomly obtained from the skeletal collection of the Department of Anatomy, Mamata Medical College. The intact, dried, and non-pathological femurs were included for the present study. Femur with any fracture, un-ossified or pathological abnormalities like tumours, deformities were excluded from this study.

After obtaining Institutional Ethical committee clearance, following parameters were taken with the aid of anthropological instruments like osteometric board, goniometer and vernier calliper.

The femoral length: Is the distance from the highest point of the femoral head to the lowest point of the medial condyle measured using the osteometric board. (Fig 1)

The anterior neck length: is the distance between the base of head \& intertrochanteric line at the junction of the front of neck with the shaft. It is measured with the help of vernier calliper. (Fig 2)

The transverse diameter of head of femur: is the maximum antero-posterior distance of head of femur, which is measured with the help of vernier calliper.

The femoral neck shaft angle: is the angle made by the axis of the neck with the axis of the shaft. The axis of the neck \& axis of the shaft were measured respectively as the line joining the two centre points on anterior surface of neck $\&$ the line joining the two centre points on anterior surface of shaft. It is measured with the help of goniometer.

Fig. 1: Femur length measurement using osteometric board.

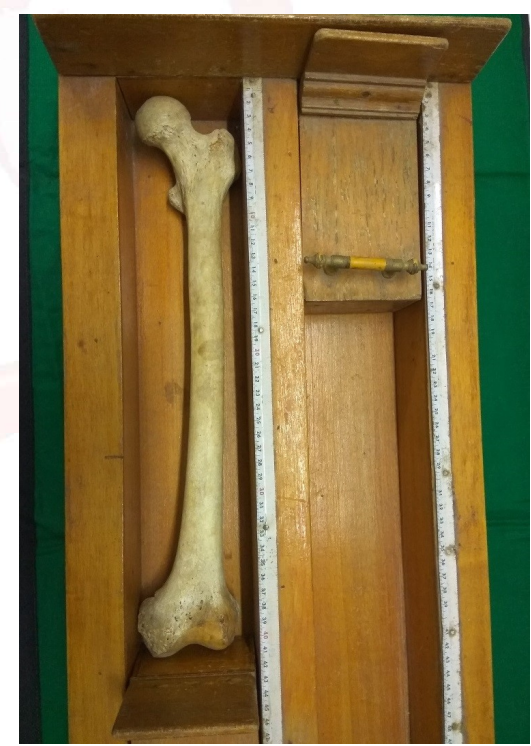

Fig. 2: Anterior neck length measurement using Vernier calliper.

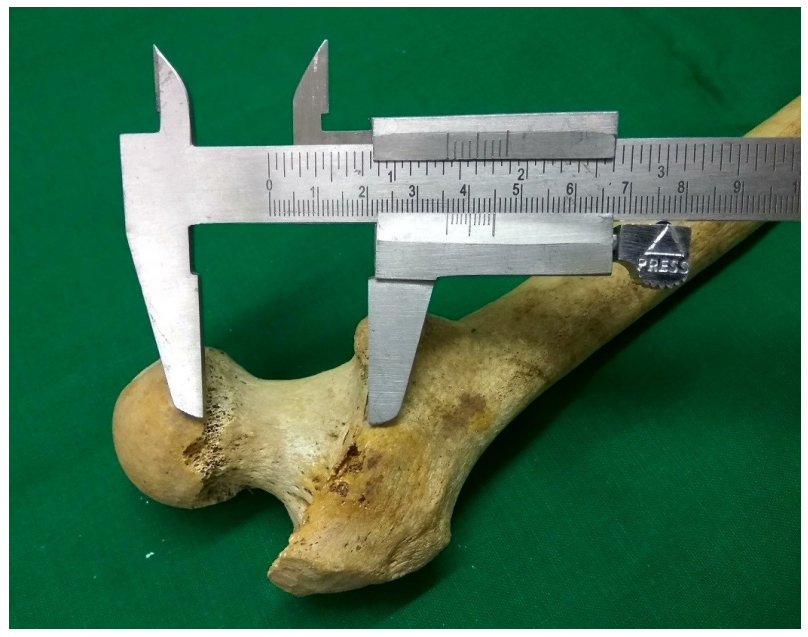


All the measurements for right and left femur were recorded separately. The data was recorded in MS Excel sheet and analysed using SPSS software $\mathbf{2} 20$ for mean \pm SD. Independent t-test was used to calculate the differences in the parameters of right and left femur. The $p$-value $<0.05$ was considered statistically significant.

\section{RESULTS}

This study was performed on 180 fully ossified, dried femur bones. The average femoral length for entire femur was $43.15 \pm 2.98 \mathrm{~cm}$, femoral head diameter was $4.09 \pm 0.35 \mathrm{~cm}$, anterior femoral neck length was $2.64 \pm 0.37 \mathrm{~cm}$, and femur neck shaft angle was $120.13^{\circ} \pm 5.72$.

Table 1 summarizes the mean, range and standard deviation (SD) of different parameters of right and left femur.

Table 1: Different parameters of right and left femurs.

\begin{tabular}{|c|c|c|c|c|c|c|c|}
\hline \multirow{2}{*}{ Parameters } & \multicolumn{3}{|c|}{ Right } & \multicolumn{3}{|c|}{ Left } & \\
\hline & Mean & Range & SD & Mean & Range & SD & p value \\
\hline Femur length & 42.95 & $32.7-47.9$ & 3.29 & 43.33 & $36.3-50.6$ & 2.72 & 0.079 \\
\hline Femur head & 4.06 & $3.3-4.83$ & 0.36 & 4.11 & $3.14-4.72$ & 0.33 & 0.58 \\
\hline Femur neck length & 2.69 & $1.36-4.18$ & 0.41 & 2.61 & $1.82-3.9$ & 0.34 & 0.685 \\
\hline Neck shaft angle & 119.92 & $104-138$ & 6.27 & 120.3 & $108-132$ & 5.26 & 0.138 \\
\hline
\end{tabular}

\section{DISCUSSION}

Anthropometry provides various techniques and scientific approaches for taking number of measurements in the different races and geographical regions. Several studies on morphometry of femur have been performed in various locations. Several authors used different materials and techniques such as cadaveric specimens, dry bones, plain radiographs, Computed Tomography (CT) scans and Magnetic Resonance Imaging (MRI) scans to study the different parameters of femur.

In total hip arthroplasty, the design and dimensions of femoral component should match the dimensions of proximal femur [10]. If the implant is inappropriate, hip dislocation and

Table 2: Length of femur among various studies.

\begin{tabular}{|c|c|c|}
\hline Author & Right side & Left Side \\
\hline Gujar et al [12] & 43.99 & 43.65 \\
\hline Dhivya et al [13] & 41.29 & 41.88 \\
\hline Khan et al [6] & 44.66 & 44.58 \\
\hline Sundar et al [4] & 45.28 & 45.13 \\
\hline Present study & 42.95 & 43.33 \\
\hline
\end{tabular}

Int J Anat Res 2020, 8(1.1):7247-50. ISSN 2321-4287 fractures of the implant are quite common [11]. Mean value of maximum femur length on left side was higher than on the right side. Comparison of femur length by various studies is tabulated in table 2.

Some commonly described measurements that are associated with an increased risk of fracture include a longer hip axis, femur length, a greater neck shaft angle and a larger width of femoral neck. In the present study, mean anterior neck length on right side was $2.69+0.41$ $\mathrm{cm}$ and the left side was $2.61+0.34 \mathrm{~cm}$, which is less than study of Ravichandran et al [9] and Sundar et al [4].

It is quite common to have proximal femur fractures, including neck and trochanters. Internal fixation with implants for these fractures are important for rehabilitation and early mobilization of the patients. The transverse head diameter of right femur was $4.06 \pm 0.36 \mathrm{~cm}$ and the left femur was $4.11 \pm 0.33 \mathrm{~cm}$ which is greater than the Nidugala et al values and smaller than Rajeev et al and Cihan et al studies. Several previous studies on adult femur have been conducted in various nations like Pakistan, Brazil, Nepal, Malaysia and China $[14,15]$.

The collo-diaphyseal angle is a significant factor particularly in operations involving the dynamic hip screw and dynamic condylar screw. The average neck shaft angle of right femur was $119.92^{\circ} \pm 6.27$ and left femur was $120.3^{\circ} \pm 5.26$. Table 3 shows the comparison of neck shaft angle of various authors.

Table 3: Comparison of mean neck shaft angle (NSA).

\begin{tabular}{|c|l|c|c|}
\hline SI no & \multicolumn{1}{|c|}{ Author } & Region & Mean NSA \\
\hline $\mathbf{1}$ & Toogood et al [14] & USA & $129.23^{\circ}$ \\
\hline $\mathbf{2}$ & Ravichandran et al [9] & India & $126.55^{\circ}$ \\
\hline 3 & Davivongs et al [16] & Australia & $127.60^{\circ}$ \\
\hline 4 & Da Silva et al [15] & Brazil & $122.55^{\circ}$ \\
\hline 5 & Bada and Endo et al [17] & China & $125.60^{\circ}$ \\
\hline 6 & Present study & India & $120.13^{\circ}$ \\
\hline
\end{tabular}

Implants were mostly produced by European and American manufacturers to replace the diseased hip joint, probably using the morphometric features of their respective population. These implants come in various sizes to match their population. Nevertheless, local surgeons have less selection of size available to them due to the relatively small built size of our population. 


\section{CONCLUSION}

In total hip replacement, proximal femur morphometry is an essential parameter for the design and development of implants. The present study made an effort to build data on various dimensions of proximal end femur among Telangana population. We would like to emphasize the importance of proximal end of femur morphometry, especially the collo-diaphysial angle, head diameter and length of the femoral neck that differ from other populations.

We assume that the obtained results will help in surgical interventions of proximal femur and arthroplasty procedures. It enlightens the biomechanical engineer to prepare implant design according to measurements of the local population. There is no statistically significance difference between right and left femur measurements. The knowledge of morphometry of proximal end of femur will be useful in anthropological and medico-legal practice, as well as to orthopaedicians for diagnosis and treatment of disease related to hip and femur.

\section{Conflicts of Interests: None}

\section{REFERENCES}

[1]. Moore KL, Dalley AF. Clinically Oriented Anatomy: 6th ed. Philadelphia / Elsevier; 2010. P. 517-20.

[2]. Standring S, Borley NR, Gray H. Gray's anatomy: the anatomical basis of clinical practice. 41st ed. Edinburgh: Churchill Livingstone/Elsevier; 2016. P. 1379-42.

[3]. Sobana M, Nedunchezhiyan S. Osteometric study of proximal femur. Int J Anat Res 2019;7(1.1):61086112.

[4]. Sundar G \& Sangeetha V. Morphometric study of human femur. Ind Jr of Med Research and Pharma Sciences. 2018;5(3):52-55.

[5]. Peter E L, Pavani Marapaka. Examination evaluation and statistical analysis of human femoral anthropometry in Hyderabad and Secunderabad regions, India. Ind Jr of Clin Anat and Phy. 2016;3(4);427-432.
[6]. Shakil Mohamad Khan, Shaik Hussain Saheb. Study on neck shaft angle and femoral length of south Indian femurs. Int J Anat Res. 2014;2(4):633-635.

[7]. Mahesh Vemavarapu, Jyothinath Kothapalli, Vijayendranath, Kulkarni. Estimation of collo-diaphyseal angle of femur by Martin's dioptrograph: a comparative study. Int J Anat Res 2016;4(1):17721776.

[8]. Mrunal Muley, Pritha Bhuiyan. Morphometric study of neck of dry adult femora. Int J Anat Res 2017;5(3.2):4317-4320.

[9]. Ravichandran D, Muthukumaravel N, Jaikumar R, Das H, Rajendran M. Pxoximal femoral geometry in Indians and its clinical applications.J.Anat. Soc.India 2011;60(1):6-12.

[10]. Noble PC,Jerry W, Alexander JW et al. The anatomical basis of femoral component design. Clinical Orhp 1998; 235:148-165.

[11]. Gnudi,S, Ripamonti,C, Lisi L, Fini M, Giardino R. \& Giavaresi G. Proximal femur geometry to detect and distinguish femoral neck fracture from trochanteric fractures in post menopausal women. Osteoporos. Int. 2002; 13:69-73.

[12]. Gujar S, Vikani S, Parmar J, Bondre KV. A Correlation between Femoral Neck Shaft Angle to Femoral Neck Length. Int J Biomed \& Adv Res 2013; 4(5): 295-298.

[13]. Dhivya S, Nandhini V. A Study of Certain Femoral Metrics in South Indian Population and its Clinical Importance. Int J Sci Stud 2015; 3(7):132-135.

[14]. Toogood PA, Skalak A, Cooperman DR. Proximal femoral anatomy in the normal human population. ClinOrthopRelat Res 2009;467:876-85.

[15]. Da Silva V, Oda JY, Santana DMG. Anatomical aspects of the proximal femur for adult Brazilians. Int. J. Morphol. 2003;21(4):303-8.

[16]. Davivongs V. The femur of the Australian Aborigine. American Journal of Physical Anthropology. 1963 Dec;21(4):457-67.

[17]. Baba H, Endo B. Postcranial skeleton of the Minatogawa man. In The Minatogawa Man. The Upper Pleistocene Man from the Island of Okinawa (ed. Suzuki H, Hanihara K) Bulletin of the University Museum, University of Tokyo 1982:19:61-195.

How to cite this article:

Vinay G, Naveen Kumar B, Kalpana Thondapu. MORPHOMETRIC STUDY OF PROXIMAL END OF FEMUR IN TELANGANA POPULATION. Int J Anat Res 2020;8(1.1):7247-7250. DOI: 10.16965/ ijar.2019.350 